\title{
Using Capstone Projects for Community Outreach
}

\section{Dr. Carmen Cioc, The University of Toledo}

Dr. Carmen Cioc is Assistant Professor and MET Program Director in the Engineering Technology Department, College of Engineering, at the University of Toledo. She received her Master in Aerospace Engineering from The University Politehnica of Bucharest, her Master in Physics - Professional in Photovoltaics, and her Ph.D. in Engineering, in the field of thermal sciences, from The University of Toledo.

Dr. Sorin Cioc, The University of Toledo

Mr. Richard A. Springman P.E., The University of Toledo

Prof. Springman is the Associate Chair and Director of Student Support of the Engineering Technology Department in the College of Engineering at The University of Toledo. He is also the Senior Technology Capstone course coordinator. 


\section{Using Capstone Projects for Community Outreach}

\section{Introduction}

The Capstone Projects course is certainly one of the most important courses the students experience in our college. In the Mechanical Engineering Department and in the Engineering Technology Department capstone project courses, students are exposed to and demonstrate their abilities listed in most, if not all, ABET student outcomes a-k. Still, in our experience, not all projects provide strong components related to student outcomes h (broad education), $\mathrm{j}$ (knowledge of contemporary issues), and i (life-long learning). In this context, this work shows some of our experiences in implementing projects originating from the community where our university is located. In particular, this work presents two cases: (i) one project to satisfy the need of an elderly resident to move larger items with his pick-up truck and (ii) one project based on the idea proposed by a local inventor related to power production. In both cases the clients have no engineering background, but they are confronted with problems that can be solved through engineering design.

As opposed to other projects, such as those related to people with physical disabilities or those with local industrial partners, in these community-related projects the clients were very closely involved in the design process, although not as engineers.

By working on such projects, our students were able to interact with and learn from people of different backgrounds; this interaction, while not always simple, benefitted both our students and their clients. They were also able to see firsthand the positive impact their work can have on people's lives: transforming a dreamed idea into a physical prototype, or helping a member of our community with his daily activities. Finally, by directly interacting with people who continue to propose new ideas and lead active lives with new problems, even after retirement, our students experienced the importance that life-long learning and intellectual curiosity have on people's lives.

Our experience has been largely positive and we plan to expand our capstone project list to include more such projects.

\section{Project \#1: EZ Loader - Fall 2017}

This project was developed by five students enrolled in the Engineering Technology Department. Two of them graduated with a major in Mechanical Engineering Technology (MET), two with a major in Electrical Engineering Technology (EET), and one with a major in EET with ME concentration. The mechanical engineering majors designed and laid out the EZ Loader prototype, including developing designs, machining, fabrication, and assembly for the mounting points, bevels, housings, the conveyor and the roller assembly. The electrical engineering majors designed the electrical parts of the EZ Loader, wired and tested the motor and controller and hooked up the power source. 
Project motivation: The project was initiated by a faculty whose elderly father faced significant difficulties when loading and unloading certain items into his truck. He was often in painful positions or straining to climb into the truck bed during this process, risking physical injury. Since neither the faculty nor his father were engineers by profession, it was difficult for them to find a solution to these issues.

Consequently, the team's primary objective was to design a pickup truck conversion for disabled and elderly persons to aid in the loading and unloading of large and/or heavy objects on the truck bed. Other objectives included time savings, reduced physical effort, improved ergonomics, and uncompromised safety to avoid bodily injury.

Design and analysis process: The team identified three major decisions required to solve the problem:

a) The team decided on adding a type of conveyor on the pickup truck bed. Different materials and components required to construct a conveyor, such as the belt, rollers, motor, power source, and controller were researched. Three designs were considered: i) using two tracks in the truck bed, one on each side; ii) using a track to one side of the truck bed; iii) using one track in the middle of the truck bed. The team also investigated the need of a ramp to the ground as part of the conveyor system, or a winch, or lift system to the tailgate of the pickup truck. After considering the time restrictions, it was determined that these additional features were beyond the scope of the proposed project but could be added later on as potential improvements to the basic design.

b) A second decision was whether to make the conveyor system from scratch or out of readily available parts.

c) A third decision was to identify the power source for the proposed mechanism.

Based on design analysis, it was determined that continuing the conveyor system onto a ramp would not allow the tailgate to close after loading cargo. It was also decided to use a refurbished treadmill, provided free of charge by a local physical fitness company, as a conveyor system since it would eliminate a significant amount of design/build time and could handle weights up to 300 hundred pounds. To test and develop the proposed solution, the team acquired a truck bed donated by a local auto parts company.

The used treadmill was assessed for working parts and the parts not needed were cut and grounded off. Mounts to install the treadmill on the truck's bed were built and installed.

In order to move the cargo from the tailgate onto the conveyor, a roller/slider system was designed in such a way that when attached to the tailgate it will allow it to be closed. This system consisted of 1.5-inch PVC pipe placed over 1-inch wooden dowels that were mounted on a wooden frame with heavy duty drawer slides. Inward folding bevels to cover the wheels housing inside the truck bed were constructed and installed, as seen in Figure 1. The team decided that this design would direct cargo onto the conveyor and eliminate wasted space. With the inward folding bevels, storage space under them can be used and they could be folded flat on top of the conveyor when it was not in use. 


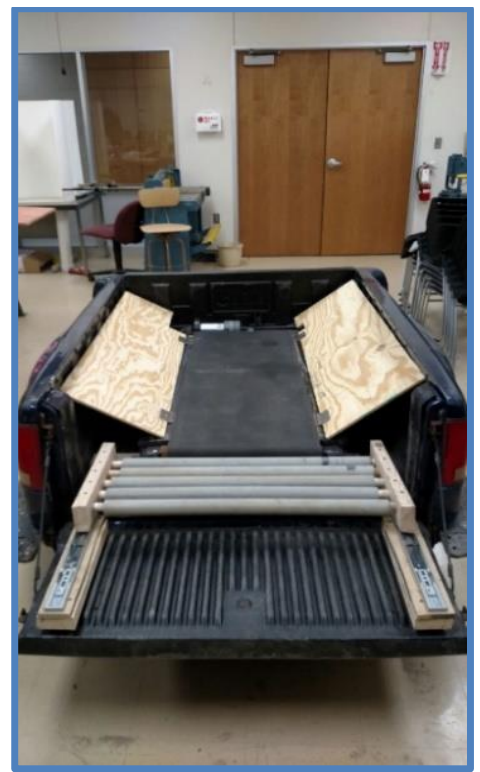

Figure 1: Installed Roller/Slider \& Folding Bevels

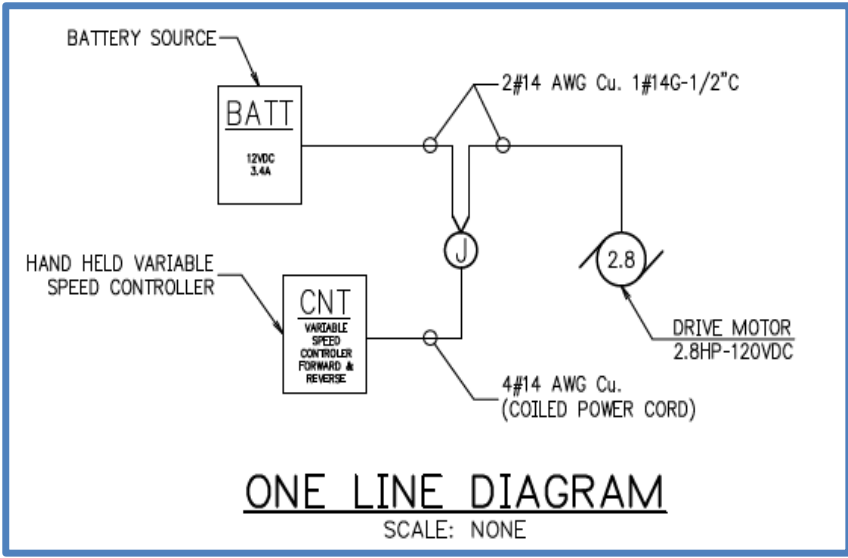

Figure 2: Final Wiring of the Conveyor System

The treadmill motor and control board were tested to determine if they worked properly and if they were compatible with the proposed design. A power source that would work with the motor and the control board and perform the required functions had to be identified. It was decided to power the motor using a standard rechargeable car battery. Since the treadmill was originally intended to be used indoors and powered using a U.S. standard $120 \mathrm{~V} \mathrm{AC} 60 \mathrm{~Hz}$ wall receptacle, it was necessary to power the motor through a control board transforming the $120 \mathrm{~V}$ AC to a usable DC voltage. It was concluded that the brushes within the motor would allow it to run in both forward and reverse and therefore will help with the loading and unloading to and from the truck bed. A variable speed control board with both forward and reverse capabilities was selected. Unfortunately, once the controller was received, the motor was wired to the controller, and the controller to the battery to test the system, there was no response from the motor. All connections, wiring, and possible issues were double checked, and after the system troubleshooting was completed, it was confirmed that the original treadmill motor was inoperable. Due to time constrictions, it was decided to purchase a new motor, especially since refurbishing the motor mount and drive belt would have presented even more problems that may not have allowed the prototype to be completed within the required timeline. The new motor and controls successfully worked as intended. The final wiring of the conveyor system is shown in Figure 2.

The remaining issues pertaining to the electrical portion of the project were related to the DC circuit and the length and gauge of the wires used. After completing the wiring, finalizing the controller location, and designing the electrical system, the system was ready for the final testing. Unfortunately, during this test, it was observed that the system did not provide the same power as in the initial test and as desired. Calculations were performed confirming the voltage drop from the source to the motor and showed that it was well above the $3 \%$ typically desired for DC circuits in industry. 
In order to meet the desired results, the wire size had to be increased or a second battery had to be added. The increase in wire size was the chosen solution.

Figures 3 and 4 show the process of rewiring the motor and the finished controller, magnetically attached to the truck bed.

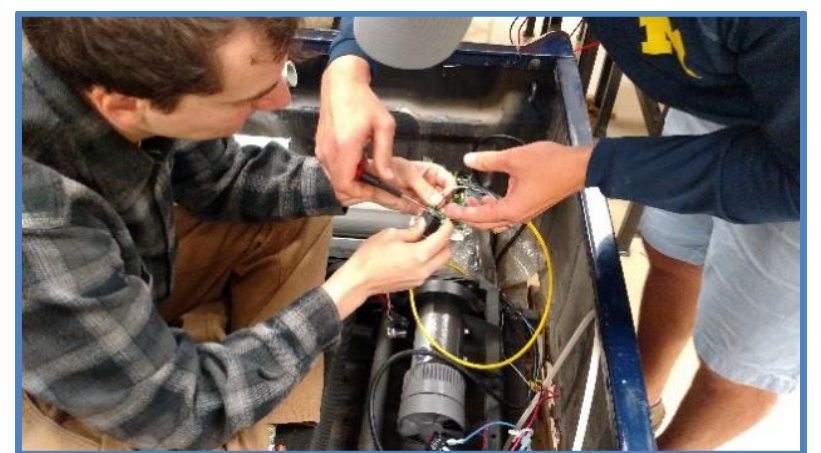

Figure 3: Motor and Controller

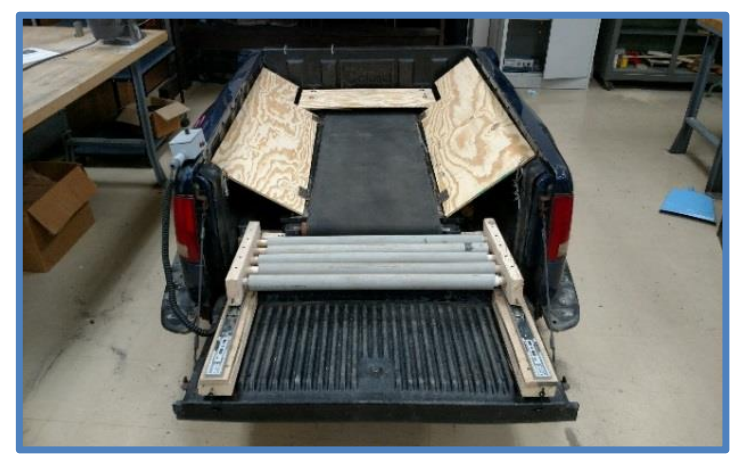

Figure 4: Finished Prototype

The finished prototype of the EZ Loader is a unique built-in solution sized for a typical pickup truck. The conveyor is able to handle loads of up to 300 pounds. The controller is movable and can be attached to virtually any location on the truck by means of magnets. Rollers are attached to the tailgate on a sliding base to allow easy loading onto the conveyor belt. The roller mechanism is constructed to allow the tailgate to close once the freight has been loaded. The controls allow the user to move the freight to the front of the truck bed on the conveyor belt at the user's desired speed. When the user arrives at the unloading destination and the tailgate is lowered, the controls reverse the direction of the conveyor belt to move the load back onto the tailgate of the truck. The sliding base pulls the load to the end of the tailgate where it can be lifted to ground level. Future versions of the EZ Loader can include a lift from ground level to the tailgate.

\section{Project \#2: Hydroelectric Power Plant - Fall 2016 and Spring 2017}

Project motivation: The client, an inventor and retired teacher living in our area, wanted to see his dream become a reality. He has been working for the past ten years on various hydroelectric power production methods that would allow small-height water dams to be able to produce electricity efficiently and at a reasonable cost. Not being an energy or hydraulics specialist, the client had in mind a fairly complex system, difficult to build and to control its operation. Some of his design ideas were not developed in a scientific way and a few misconceptions were also present. Two senior design teams in the mechanical engineering science department, in two consecutive academic terms, selected this project for their senior design course and they were advised by one of this paper coauthors.

Project design and analysis: One of the first tasks the senior design teams had to do was to understand the fluid mechanics principles underlying the proposed design by translating the client's ideas into engineering design ideas and interacting with the client both to fully understand his proposed concepts and also to present him their own views on how the design should progress. In this phase, our students had to research and study different concepts of micro-head power production and the impact of hydroelectric power in today's energy climate 
(ABET outcomes $h$ and $j$ ); the Department of Energy currently actively encourages the advancement of these types of hydroelectric power plants, recognizing that the vast majority of good sites (large head) hydroelectric power plants in North America have already been developed ${ }^{1}$. Our students also experienced firsthand how novel ideas can be sourced from people of different backgrounds and ages as long as individuals continue to learn and use their knowledge and ideas (ABET outcome i). These powerful novel ideas can contribute to solving important contemporary problems (energy in this case).

Both teams of students followed the engineering design principles and steps as part of their coursework. They applied the fundamental equations of fluid mechanics (continuity, momentum, and energy equations) in their design. The prototype design developed by the first team is shown in Figure 5a as a three-dimensional (3D) computer model. The design requires a water source and water discharge. They also built the prototype (Figure 5b), although they were not able to fully finalize it due to time and cost constraints.

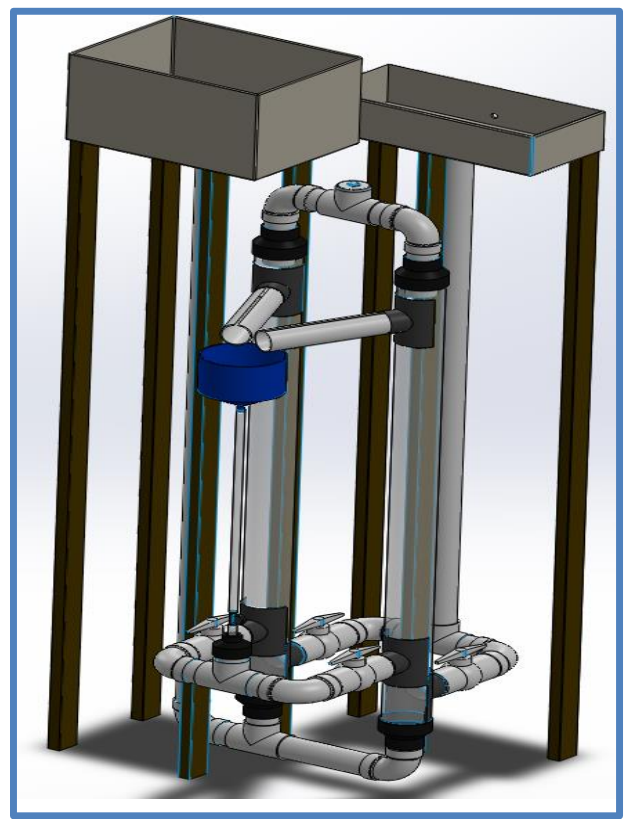

(a)

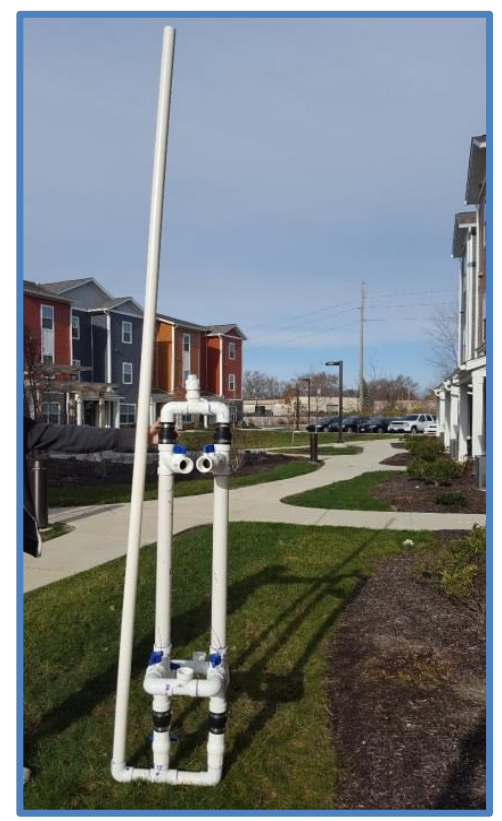

(b)

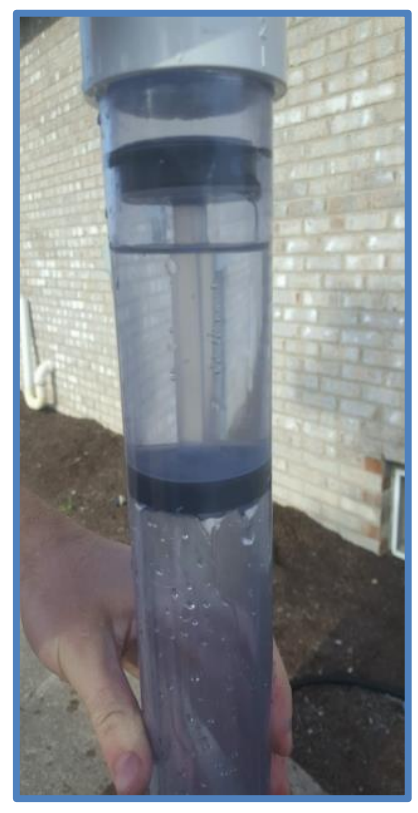

(c)

Figure 5: Hydroelectric power prototypes: (a) First design 3D model, (b) First design prototype being built, and (c) second design piston sealing

The second team, in the following term, made significant changes to the design by enlarging the pipes and implementing new sealing solutions for the moving pistons inside the tubes (see Figure 5c). They also designed an automated control system using a Raspberry Pi and electromechanical solenoid valves. The final prototype showed that the proposed concept was valid, but the efficiency was very low due to the small size of the prototype, as friction plays a relatively larger role at small scale, and due to the complexity of moving pistons and electrically powered valves. Encouraged by the experience but understanding the intrinsic limitations of scaling, the client worked on a new design, with less moving parts and thus less friction, which is currently being designed and built by a third senior design team during the spring term 2018.

The client sponsored all three projects and has been continually involved in all aspects of the design and building of the prototype; his interactions with our students and the adviser have been only positive and beneficial for all parties involved. 
The community outreach has been a constant over the years, with faculty from our departments involved in many other community outreach projects, such as:

- Spring 2018: Motorized Cart for a Local Greenhouse - Work in progress. The authors advise a group of 5 MET students involved in another community outreach project: the development of a motorized cart for a local tomato grower. The cart is required to move front and back through the tomato rows as well as up and down to ease the tomato harvesting.

- Spring 2016: Boy Scout Camp Aquatic Center. The goal of the project was to design an Aquatic Center for a Boy Scout Camp near a lakeside located in Pioneer, OH. There was the need to create a functional aquatic center that can serve recreational and educational activities.

- Spring 2015: Harvest Baptist Church Sports Complex. The project was to design an indoor sport complex capable of housing multiple sports programs and events for the Harvest Baptist Church located in Wapakoneta, OH. The team designed a 45,900 $\mathrm{ft}^{2}$ single story building with a $18,000 \mathrm{ft}^{2}$ basement. Housed within the structure are two artificial turf football fields, basketball court, multipurpose rooms, as well as facilities for concessions.

o Spring 2014: Community Park Development. The project was to design a park to benefit the local community as well as the St. James Lutheran Church. The proposed plan included a mix of outdoor sporting activities, a pavilion with seating and grills, open greenspace and restroom facilities. The park is intended to improve the overall look, happiness and health of the surrounding community and to provide a place to relax and enjoy friends and family outdoors.

- Fall 2013: Solar Water Heating in Costa Rica: The goal of the project was to investigate the feasibility of using solar energy to heat water for kitchen use in a remote location in Costa Rica. Photovoltaic (PV) panels, wiring and a water heater would be used rather than pumps, pipes, rooftop heaters, and supply tanks associated with a traditional hydronic system. A cost-effective means of heating water is particularly important for the region where access to reasonably priced electricity is limited.

\section{Conclusion}

Community outreach is a powerful tool to focus the energy of our students when applying their engineering knowledge during the senior design course. We noticed that every time when such projects were available, they were selected high on the preference list (list used to assign projects to various teams). Our experience has been mostly positive, with the students producing excellent designs and working prototypes, while having a good experience through interaction with people from the community in need of engineering solutions. Some of the advantages observed are:

$\circ$ Wide variety of projects, in different areas, thus able to address a wide variety of students' interests

○ Reciprocally beneficial interaction with people from various backgrounds and age 
- High project satisfaction rates, as students are able to directly and positively influence people lives as opposed to industrial projects where generally projects address cost or time savings

- Experiencing firsthand how novel ideas require dedication and lifelong learning

- Increased involvement of the faculty advisors in the community

- Addressing more "difficult" ABET outcomes, such as h, i, and k

Potential drawbacks for such projects may be their complexity and possible unrealistic expectations from the project clients. These potential disadvantages must be considered and proactively addressed by the academic advisor(s) when interacting with the clients and when guiding the students along their design process.

References:

1 U.S. Department of Energy, "Hydropower Vision: A New Chapter for America's 1st Renewable Electricity Source", https://energy.gov/eere/water/articles/hydropower-vision-newchapter-america-s-1st-renewable-electricity-source 